\title{
AS PRÁTICAS MISSIONÁRIAS BATISTAS NO VALE DO RIO TOCANTINS ENTRE 1925 E 1940: APONTAMENTOS HISTÓRICOS PARA A COMPREENSÃO DE UM EVANGELISMO CONSERVADOR
}

Baptist missionary practices in the tocantins river valley between 1925 and 1940:

Historical notes for understanding a conservative evangelism

Práticas misioneras bautista en el valle del río tocantins entre 1925 y 1940: Notas

históricas para comprender um evangelismo conservador

\section{Wedster Felipe Martins Sabino*1, Vasni de Almeida².}

${ }^{1}$ Mestrando em História Social pelo Programa de Pós-Graduação em História Social da Universidade de São Paulo (PPGHS - USP). Licenciado em História pela Universidade Federal do Tocantins (UFT), Campus de Porto Nacional. Bolsista de Iniciação Científica do Conselho Nacional de Desenvolvimento Científico e Tecnológico (CNPq) desde 2018.

${ }^{2}$ Doutor em História pela Universidade Estadual Paulista "Júlio de Mesquita Filho" (UNESP-Assis). Professor do Curso de Licenciatura em História da Universidade Federal do Tocantins (UFT), Campus de Porto Nacional. Coordenador do Programa de Pós-Graduação em História das Populações Amazônicas (PPGHispam - UFT).

*Correspondência: Núcleo de Estudos das Diferenças de Gênero (NEDIG), Universidade Federal do Tocantins, Campus de Porto Nacional, Rua 03, Quadra 17, Lote 11, s/no , Porto Nacional, Tocantins, Brasil. CEP:77.000-00. e-mail wedstersabinohist@gmail.com

\section{Artigo recebido em 25/03/2020 aprovado em 07/11/2020 publicado em 01/12/2020.}

\section{RESUMO}

Atualmente, um debate que envolve os grupos evangélicos no Brasil, desde a primeira década do século XXI, é o referente à natureza conservadora de posturas e práticas dos líderes de igrejas pentecostais e neopentecostais em relação a temas que remetem a questões de cunho moral (aborto, homossexualidade, drogas, entre tantos) e político (liberalismo, comunismo, socialismo, fascismo, entre outros temas). De nosso lado, entendemos que embora tenha havido um aprofundamento do conservadorismo evangélico no Brasil, notadamente após 2016, essa face conservadora é mais antiga do que leva a crer as generalizações recentes. E que ela não fica restrita a essas duas tendências religiosas. Nesse sentido, o objetivo deste trabalho é problematizar a face conservadora de grupos, líderes e instituições religiosas, através de apontamentos históricos das missões protestantes instaladas no Brasil, durante as primeiras décadas do século XX. Em especial, o plano de evangelização da Convenção Batista Brasileira para o Vale do Rio Tocantins iniciado em 1925, A Pátria para Christo. O estudo ancora-se nas perspectivas teóricas e metodológicas da História Cultural e da História das Religiões, auxiliadas pelos conceitos de campo e campo religioso, cunhados pelo sociólogo francês Pierre Bourdieu.

Palavras-chave: História das religiões; protestantismo; conservadorismo.

\section{ABSTRACT}

Currently, a debate involving evangelical groups in Brazil, since the first decade of the 21 st century, is related to the conservative nature of postures and practices of Pentecostal and Neopentecostal church leaders in relation to issues that refer to moral issues (abortion), homosexuality, drugs, among many) and political (liberalism, communism, socialism, fascism, among other themes). On our side, we understand that although there has been a deepening of evangelical conservatism in Brazil, notably after 2016, this conservative face is older than what recent 
generalizations believe. And that it is not restricted to these two religious tendencies. In this sense, the objective of this work is to problematize the conservative face of religious groups, leaders and institutions, through historical notes of the Protestant missions installed in Brazil, during the first decades of the 20th century. In particular, the evangelization plan of the Brazilian Baptist Convention for the Tocantins River Valley started in 1925, The Homeland for Christ. The study is anchored in the theoretical and methodological perspectives of Cultural History and the History of Religions, aided by the concepts of field and religious field, coined by the French sociologist Pierre Bourdieu.

Keywords: History of religions; protestantism; conservatism.

\section{RESUMEN}

Actualmente, un debate que involucra grupos evangélicos en Brasil, desde la primera década del siglo XXI, está relacionado con la naturaleza conservadora de las posturas y prácticas de los líderes de las iglesias pentecostales y neopentecostales en relación con cuestiones que se refieren a cuestiones morales (aborto), homosexualidad, drogas, entre muchas) y políticas (liberalismo, comunismo, socialismo, fascismo, entre otros temas). De nuestro lado, entendemos que, aunque ha habido una profundización del conservadurismo evangélico en Brasil, especialmente después de 2016, esta cara conservadora es más antigua de lo que creen las generalizaciones recientes. Y que no se limita a estas dos tendencias religiosas. En este sentido, el objetivo de este trabajo es problematizar la cara conservadora de grupos religiosos, líderes e instituciones, a través de notas históricas de las misiones protestantes instaladas en Brasil, durante las primeras décadas del siglo XX. En particular, el plan de evangelización de la Convención Bautista Brasileña para el Valle del Río Tocantins comenzó en 1925, A Pátria para Christo. El estudio está anclado en las perspectivas teóricas y metodológicas de la Historia Cultural y la Historia de las Religiones, ayudado por los conceptos de campo y campo religioso, acuñado por el sociólogo francés Pierre Bourdieu.

Descriptores: Historia de las religiones; protestantismo; conservadurismo.

\section{INTRODUÇÃO}

Um debate que envolve os evangélicos protestantes no Brasil, desde a primeira década do século XXI, é o referente à natureza conservadora de posturas e práticas dos líderes de igrejas pentecostais e neopentecostais em relação a temas que remetem a questões de cunho moral (aborto, homossexualidade, drogas, entre tantos) e político (liberais, comunistas, socialistas, fascistas, entre outros temas). Há quem considere que o pentecostalismo e neopentecostalismo, fenômenos no interior do evangelismo protestante brasileiro, que ganharam fôlego a partir da década de 1970, são os responsáveis por essa ascensão conservadora. De nosso lado, entendemos que embora tenha havido um aprofundamento do conservadorismo evangélico no Brasil, notadamente após 2016, essa face conservadora é mais antiga do que leva a crer as generalizações recentes. E que ela não fica restrita a essas duas tendências.

Em capítulo em que debruçamos sobre a temática modernidade protestante no Brasil na primeira metade do século XX (ALMEIDA, 2017), procuramos apontar, por meio de considerações de autores e autoras que pesquisam com cuidado a história do protestantismo brasileiro, que a ideia de um protestantismo tradicional liberal, progressista e moderno em contraposição à moralidade conservadora de pentecostais e neopentecostais deve ser relativizada.

Nos estudos citados acima, onde buscamos fazer emergir o pêndulo das práticas religiosas e sociais das igrejas protestantes tradicionais, estas práticas se encontram, ora marcadas pela modernidade, ora pelo conservadorismo. Neste sentido, em $O$ protestantismo no Advento da República no Brasil: discursos, estratégias e conflitos 
(2010), Lyndon de Araújo Santos entende que a visão compartilhada entre os missionários protestantes e políticos liberais das primeiras décadas do século XX seria a de que o protestantismo se posicionava como uma religião esclarecida, muito em razão de sua oposição ao catolicismo. Em um ambiente marcado pela escravidão, pelo analfabetismo e pela desigualdade social, os protestantes, vistos como um grupo religioso exótico, trataram de criar um discurso que os colocavam como agentes da modernidade, usando como contraponto o fato de o catolicismo não corresponder mais as exigências de uma sociedade em pleno processo de mudanças políticas, econômicas e sociais. Para Santos, todavia, havia um descompasso entre o discurso liberal e as práticas das principais lideranças do protestantismo, pois com "base nas ideias liberais e na leitura da Bíblia, missionários e pastores protestantes denunciaram a escravidão como sistema desumano, mas pouco ou nada participaram na causa da abolição do sistema escravista". Segundo o autor, quando a República foi tomada como sistema necessário para a modernização do país, o discurso protestante foi ajustado a "outros discursos correntes no período como a modernidade, a civilização, a higienização, a ciência e a tecnologia. Esta adesão fazia parte da estratégia de construir sentidos e identidades numa sociedade sujeita a rápidas mudanças na direção da modernização e da urbanização" (2010, p. 108-110). Para Santos, a modernidade oferecida pelos protestantes estava ancorada numa moralidade muito peculiar: "aspectos como a submissão às leis, a defesa do casamento civil e a obediência, provavelmente, ao código de conduta pública, eram parte do espírito protestante expresso na pureza da moral e da higiene pessoal” (2010, p. 114).

Elizete da Silva nos ofereceu também compreensões dessa modernidade plasmada na moralidade contida na ética protestante. Em $O$ protestantismo e as questões sociais (1996), ao analisar os discursos de missionários que organizaram igrejas protestantes no Brasil, aponta que a visão pietista e individualista de separação entre vida religiosa e vida social, típica da reforma do século $\mathrm{XVI}$, tomou conta do protestantismo brasileiro na virada do século XIX para o XX. O mundo, para os missionários norte-americanos que organizaram igrejas no Brasil, era visto como espaço do mal, espaço do pecado, do qual os crentes deveriam fugir. Dessa forma, a fome, a violência, o desemprego, a corrupção, era compreendido pelo protestantismo e ensinado em escolas dominicais e nos espaços de comunicação das igrejas, como males decorrentes de ações individuais e nunca sociais. (1996, p. 134). Para Silva, os missionários entendiam que para que os brasileiros atingissem a civilidade e progresso dos norteamericanos, bastava que indivíduos fossem convertidos à fé protestante. Nesse discurso conversionista não caberia, no entanto, acões políticas de contestação, pois o fundamentalismo das igrejas missionárias implantadas no Brasil, mesmo com o advento da República, negava a ação política. Por meio de estratégias de ensino em escolas, cultos, materiais impressos, o pietismo fincou entre os fiéis brasileiros a ideia da acomodação ao poder político estabelecido (SILVA, 1996, p. 135-136).

João Marcos Leitão, outro pesquisador do protestantismo brasileiro, tracejou aspectos importantes do que significava modernidade para os protestantes tradicionais. Em A concepção da ordem social segundo o protestantismo brasileiro: 18911930 (2012), o autor argumenta que o protestantismo se imaginava, por meio de sua ética, precursor e defensor da democracia moderna e da ordem e que essas produziriam novos valores dentro do novo regime "desde que o homem se converta, isto é, refaça seus referentes éticos-religiosos, tornando-se, pela virtude, apto a implementar o modelo ideal de 
sociedade, que de resto constitui o substrato de toda ética religiosa" (2012, p. 149).

Leonildo Silva foi mais enfático ao analisar a face conservadora desse protestantismo que se pretendia moderno. Em $O$ protestantismo de missão no Brasil, cidadania e liberdade religiosa (2014), expressou que a mudança de regime, em 1889, foi recebida com euforia por presbiterianos e metodistas. Para esses protestantes, "a proclamação da República era um acontecimento necessário para o surgimento de um Estado laico, e para o estabelecimento definitivo da democracia no Brasil”. (2014, p. 81). O autor pondera, no entanto, que manifestações conservadoras sobre questões sociais e políticas nunca faltaram nos meios de comunicação organizados pelos protestantes brasileiros. Analisando os jornais evangélicos "O Estandarte" e "O Expositor Cristão", nos momentos da derrubada de Canudos pelas forças policiais federais, destaca que presbiterianos e metodistas aplaudiram a ação do governo, alegando que este eliminava os perigos que rondavam o progresso implantado pelo regime republicano (2014, p. 95).

Tais sentidos de modernidade protestante revelam muito dos elementos conservadores que marcam os evangélicos da atualidade, alçados que foram a agentes religiosos de grande força política. Ainda que o sentido de modernidade que emanavam estivesse alinhado ao modelo de civilização e progresso positivista, a moral que defendiam era refratária às mudanças culturais que pudessem vir do modo de vida de sertanejos, dos festejos populares, dos rituais indígenas. Esse tipo de modernidade revela o quanto os protestantes tradicionais foram instados a participarem da República instaurada em 1889. E fizeram isso a partir de uma moralidade que conservava os valores tradicionais dos grupos que

\footnotetext{
${ }^{1}$ Prescrição emblemática para o cristianismo missionário e que se encontra no Evangelho de Mc. 16:15, em: BÍBLIA SAGRADA. Tradução de João Ferreira Almeida. Rio de
}

atuavam na consolidação do regime republicano. Em suas igrejas e escolas espraiaram o que compreendiam como sendo a modernidade necessária ao país: a sua moralidade. É disso que tratamos nas práticas missionárias batistas no Vale do Rio Tocantins, nas primeiras décadas do século XX.

Para apontar os sinais da modernidade protestante, em muito restrita aos seus padrões de moralidade, dividimos o artigo em três tópicos: no primeiro, tratamos do que o protestantismo tinha a oferecer como projeto de modernização das populações do interior; no segundo, tratamos da modelo ideal de sociedade contido nas práticas religiosas batistas implantadas no Brasil a partir da segunda metade do século XIX; no terceiro, apresentamos os sinais de conservadorismo social presente nas práticas missionárias dos batistas no Vale do Rio Tocantins.

\section{AS MISSÕES PROTESTANTES E A MODERNIZAÇÃO DOS SERTÕES}

No silencio das arvores e com Deus bem perto de nós, estudámos a lição que tratava do início do movimento missionario, oriundo na igreja em Antiochia. Já se passaram muitos seculos, porém, a exemplo de Paulo e Barnabé, temos o mesmo privilegio de levar a mensagem do Evangelho aos que nunca a ouviram. Ficámos com a alma e o coração repletos de alegria, porque pudemos realizar este maravilhoso privilegio, que não só é nosso, mas de todos os filhos de Deus (OJB, 18/3/1926, ed. 10 , p. $12-14$ ).

A epígrafe coloca em relevo um dos princípios mais importantes da atuação religiosa do cristianismo: o ide por todo o mundo e pregai o evangelho a toda criatura $^{1}$. Essa sentença moldou a noção de uma religião universal, crença que tem por objetivo fazer com que os cristãos estejam legitimados a interferir em diferentes civilizações e culturas. Este princípio seria o responsável por um dos maiores movimentos da

Janeiro: King Cross Publicações, 2008. 1110 p. Velho Testamento e Novo Testamento. 
história das religiões: as missões. A prática das missões está diretamente relacionada à fundação do cristianismo e propagou-se pelo mundo de infinitas formas, sobretudo no contexto da modernidade, que tem como um de seus marcos determinantes a Reforma Protestante, em 1517, que, aliada à expansão comercial e geográfica do mundo ocidental, definiria novas e diferentes formas de evangelizar o mundo por parte de religiosos protestantes, assim como pelos próprios católicos (SILVA, 2017).

$\mathrm{Na}$ América Portuguesa, as práticas missionárias católicas, exercidas a princípio e em grande parte pelos jesuítas, e posteriormente por outras ordens religiosas, teriam grande influência na construção do que hoje conhecemos como Brasil. Topônimos (São Paulo, Santa Catarina, Espírito Santo), dias santos e feriados (12 de outubro, Corpus Christi e etc.), entre tantas outras práticas e representações encontradas no cotidiano de nossa sociedade, evidenciam uma influência não só religiosa, mas, cultural, do catolicismo sobre a sociedade brasileira (HOORNAERT, 2008). Esta hegemonia cultural da Igreja Católica no Brasil seria abalada somente a partir de 1889 , com "o advento da ordem republicana" (SEVCENKO, 1999, p. 25).

É no contexto da implantação e organização da República, momento em que a sociedade brasileira passava a ser profundamente influenciada pelas culturas norte-americanas e europeias, especialmente a francesa, que se iniciaria uma verdadeira luta pelo rompimento com os hábitos coloniais que, na visão dos intelectuais do início do século $\mathrm{XX}$, perduraram no Império, e que representavam o oposto da ordem e do progresso. "É nesse momento que se registra na consciência intelectual a ideia do desmembramento da comunidade brasileira em duas sociedades antagônicas e dessintonizadas" (SEVCENKO, 1999, p. 32), a saber: a divergência entre a sociedade moderna, saneada e civilizada das grandes cidades do litoral e a sociedade rural, indolente, enferma e caturra do interior - os sertanejos, os ribeirinhos, os indígenas. Na compreensão da intelectualidade republicana, uma deveria suprimir a outra. Para Sevcenko:

Não era de se esperar, igualmente, que essa sociedade tivesse tolerância para com as formas de cultura e religiosidade populares. Afinal, a luta contra a "caturrice", a "doença", o "atraso" e a "preguiça" era também uma luta contra as trevas e a "ignorância"; tratava-se da definitiva implantação do progresso e da civilização (1999, p. 33).

A Proclamação da República e a efervescência dos debates intelectuais sobre a formação e modernização da nação, que tomou força a partir de 1889, desencadearam projetos de integração e modernização nacional, que podemos traduzir como movimentos rumo ao interior do país. Esses movimentos estiveram pautados por diversas concepções, que visavam em seus discursos à modernização do interior, o saneamento das regiões do sertão brasileiro, retratados pelos sanitaristas como verdadeiros "pedaços do purgatório" (CAIXETA, 2014, p. 32). Dentre essas concepções, nos interessa a ideia de evangelização do sertão contida nas denominações protestantes, através das práticas missionárias que ganhavam espaço nesse período. Segundo os batistas que escreviam no "O Jornal Batista" (OJB) "por muitos annos desejámos explorar este vasto interior, para achar as mais preciosas de todas as joias: não diamantes ou ouro, mas almas immortaes de homens e mulheres que lá vivem" (OJB, 25/2/1926, ed. 8 , p. 10).

Os protestantes, seguindo os debates desencadeados pelos ideais positivistas do governo republicano, se movimentaram para ocupar um lugar específico neste movimento de modernização e integração do interior do Brasil, atuando na criação de sua própria narrativa acerca do atraso e ignorância das 
populações do interior que, para eles, estaria representado pelas práticas do catolicismo popular.

Em diversos trechos de jornais protestantes daquele período encontramos esse caráter antagônico para com o catolicismo. Sobre os templos católicos, por exemplo, o OJB publicou que "esses thesouros estão guardados no interior da igreja, emquanto que fóra dela há miseria e ruina. Possue a igreja a prata e o ouro, porém não tem o pão da vida para offerecer aos que estão clamando por elle" (OJB, 11/3/1926, ed. 10, p. 11). Segundo Luciane Silva de Almeida, esse antagonismo serviu ao protestantismo como "um (...) facilitador em sua inserção no campo religioso brasileiro e como fator de diferenciação em relação ao catolicismo no uso da relação progresso/atraso" (2017, p. 169).

Os protestantes, nas narrativas que construíram sobre as suas práticas missionárias, procuravam produzir uma distinção entre as suas missões, o seu fazer religioso, daquelas que faziam parte do catolicismo popular, amplamente difundido nas regiões que, nos discursos da época, eram retratadas como atrasadas. Dessa forma, cravariam a sua porção de espaço nos projetos de integração nacional dos governos republicanos, nem tanto no aspecto da modernização econômica e científica, mas na esfera comportamental.

Importante lembrar que a imprensa, o principal veículo de notícias e formação intelectual no contexto do Brasil republicano, foi importante também para as narrativas protestantes sobre a sociedade brasileira. Segundo Lyndon de Araújo Santos, as principais denominações evangélicas já mantinham periódicos próprios no último quartel do século XIX, com a imprensa sendo "uma das principais ferramentas utilizadas pelos protestantes para a demarcação de um discurso religioso e político, num período em que se deu a ampliação dos meios de comunicação impressa no Brasil" (2017, p. 134). Há que se lembrar que a
República, envolta nas duas principais correntes de pensamento que ditavam a Belle Époque, o cientificismo e o liberalismo, publicava em suas páginas "as diferentes práticas culturais de uma sociedade em busca do progresso" (ELEUTÉRIO, 2011. p. 83).

Assim, de acordo com Vasconcelos (2010), O OJB, fundado em 1901 e adotado como órgão oficial de comunicação batista a partir de 1910, publicava em suas páginas editoriais, noticiários, artigos e artigos de opinião voltados aos costumes do lar, evangelização das crianças, educação e analfabetismo, o saneamento, e as políticas do país, procurando orientar os batistas para uma conduta cristã reformada, que os diferenciasse dos "costumes e estruturas sociais" vigentes na sociedade da época. Da mesma forma, eram publicados os relatos e cartas oriundas dos campos missionários mantidos pela denominação no interior do Vale do Rio Tocantins, expondo no veículo oficial da denominação a narrativa de que a região estaria envolta em "trevas espirituais, morais e intelectuais" (OJB, 1\%/10/1936, ed. 40, p. 12). A narrativa batista, imbuída dos ideais de modernização, ganhava, assim, as páginas do jornal:

Diante do Evangelho vão desapparecendo o analphabetismo, o uso das bebidas toxicas, a superstição e tantos outros males communs ao sertão e incompatíveis com as leis do Evangelho. Os baptistas, patenteando a posse de uma grande cisão, estão projectando os seus esforços para o coração do Brasil, ou digamos, para o Brasil do futuro (OJB, 1\%/10/1936, ed. 40, p. 12).

A narrativa do jornal ajuda a compreender de que forma as crenças e práticas dos protestantes refletiam os projetos de formação cultural da nação. No contexto dos projetos que visavam o saneamento $\mathrm{e}$ modernização dos sertões, tais como a abertura de rodovias e ferrovias, aprimoramento da navegação dos grandes rios para escoamento da borracha produzida na região amazônica ou do café no sul, esses religiosos se apresentavam como defensores da modernidade 
republicana, "projetando os seus esforços ao Brasil do futuro" (OJB, 1\%10/1936, ed. 40, p. 12). Faziam isso por meio da divulgação de uma cultura religiosa, ética e moral que lhes eram próprias, espraiando o que acreditavam ser a correta maneira de viver, a ser adotada pelas populações tradicionais que viviam no interior do país.

\section{A INSERÇÃO DOS BATISTAS NO CAMPO RELIGIOSO BRASILEIRO}

De acordo com Pierre Bourdieu, as instituições religiosas visam "conquistar ou preservar um monopólio mais ou menos total de um capital de graça institucional ou sacramental" (2007, p. 58), dentro de um determinado campo religioso, isto é, dentro do âmbito religioso de uma determinada sociedade, sobre a qual almejam alcançar o monopólio da gestão dos bens de salvação promovendo a desapropriação “daqueles que dele são excluídos e que se transformam por esta razão em leigos destituídos do capital religioso e reconhecendo a legitimidade desta desapropriação pelo simples fato de que a desconhecem enquanto tal" (2007, p. 39). Assim, legitima-se aquilo que o sociólogo denomina como a divisão do trabalho religioso, onde uma pequena parcela da sociedade se encontra apta a pensar, produzir e distribuir os bens de salvação - dominando as instâncias intelectuais do âmbito religioso da sociedade -, enquanto que a maioria dos indivíduos é dominada ou, como consagrado no discurso religioso, salva por ele.

Utilizando-se destas premissas para analisar as disputas pelo campo religioso brasileiro, podemos afirmar que a posição hegemônica como a única instituição detentora da gestão dos bens de salvação no mercado religioso brasileiro da Igreja Católica só seria ameaçada com o advento da República. O catolicismo dispusera de posição privilegiada no Brasil desde os tempos da chegada dos portugueses, perpassando os séculos com a atuação de diversas ordens religiosas em diferentes áreas do empreendimento colonial.

Esta hegemonia só começaria a ser ameaçada quando, durante o Império, missionários enviados e mantidos por diferentes Juntas de Evangelização espalhadas pelo mundo, aproveitaram-se do liberalismo em voga no século XIX para iniciar seus projetos de evangelização. A partir da década de 1860, instalaram-se no Brasil missionários protestantes vindos da Europa e América do Norte e que, mais tarde, seriam o esteio para o estabelecimento destas denominações no país (REILY, 2003).

De acordo com Martin Dreher, o protestantismo missionário, fiel ao evangelismo proselitista, chegou ao Brasil a partir de 1855 (...) “em decorrência da conjunção de fatores provenientes do contexto histórico dos EUA, da Europa e da conjuntura brasileira". De acordo com o autor chegaram missionários de "origem congregacional, metodista, presbiteriana, batista e episcopal fundaram suas denominações no Rio de Janeiro, São Paulo, Bahia e Rio Grande do Sul” (2011, p. 15). Dentre essa leva de missionários estavam os batistas.

Segundo Elizete da Silva, o missionarismo batista que se instala no Brasil é oriundo dos Estados Unidos. Para a autora, "o contexto socioeconômico e político dos EUA, na segunda metade do século XIX, desempenhou um papel importante na expansão missionária que resultou na instalação dos protestantes, dentre eles a denominação Batista, no Brasil" (SILVA, 2011, p. 286). A autora se refere ao desfecho da guerra civil norte-americana, que para Émile G.-Léonard, "não foi propriamente uma guerra civil, mas a oposição de duas civilizações e de duas concepções de vida, com o triunfo implacável de uma sôbre outra" (1963, p. 332). A derrota dos Confederados e a ocupação do Sul pelos nortistas impulsionou a imigração destes para o Brasil. Segundo Anna Lúcia Collyer Adamovicz, o governo imperial 
havia sido um aliado dos Confederados durante o conflito, passou a oferecer as condições necessárias à instalação de imigrantes americanos no Brasil. O governo brasileiro possibilitava "aos recém-chegados transporte e acomodações, prometendo a estes agricultores a construção de uma infraestrutura capaz de suprir as necessidades de abastecimento de suas colônias e de facilitar o escoamento de seus produtos aos centros consumidores" (2008, p. 47).

Nesse contexto, uma colônia de imigrantes sulistas se instalaria em Santa Bárbara D’Oeste, no estado de São Paulo, entre eles muitos de confissão batista, o que permitiu a organização das primeiras igrejas batistas em solo brasileiro, em 1871 (SILVA, 2011, entre outros). A princípio, estas igrejas estiveram voltadas apenas para o serviço dos colonos norte-americanos, inclusive ministrando seus cultos em língua inglesa, para atender as necessidades da comunidade ali radicada.

Em 1872, “a Igreja de Santa Bárbara fez um apelo à Junta de Missões Estrangeiras dos Estados Unidos, solicitando que os batistas americanos dessem prosseguimento à obra missionária no Brasil" (ADAMOVICZ, 2008, p. 48). O pedido foi atendido e, dez anos mais tarde, a Junta de Missões Estrangeiras de Richmond, no estado da Virginia, enviou o primeiro casal de missionários para estabelecer a primeira missão batista no Brasil. Tratava-se do reverendo Willian Buck Bagby e sua esposa Anne Luther Bagby, que desembarcaram no Brasil no dia 02 de março de 1881, no Rio de Janeiro (REILY, 2003).

Um ano depois, chegaria ao Brasil o segundo casal de missionários enviado pela Junta de Richmond, Zachery Clay Taylor e Kate Crawford Taylor, em 23 de fevereiro de 1872, após uma viagem de 42 dias (REILY, 2003). Do Rio de Janeiro, os missionários seguiram para Santa Bárbara e depois seguiram para Salvador, onde estabeleceriam a primeira missão batista brasileira. Salvador, na década de 1880 detinha o segundo maior contingente populacional do império, além de ser o mais importante centro religioso do país. Segundo Reily, "após extensas viagens para descobrir o lugar mais apropriado para a sua primeira sede, os dois casais de missionários, acompanhados do exsacerdote, rumaram para Salvador da Bahía, onde se constituíram em igreja” (REILY, 2003, p. 134).

Após a chegada dos casais Bagby e Taylor a Salvador, os batistas iniciariam o seu trabalho de proselitismo entre a população da capital baiana e expandindo sua atuação para o interior, assim como para outros estados. Segundo Adamovicz, eram esses os resultados obtidos pelos missionários em 1889: “(...) organização de oito igrejas, a filiação de 312 membros a estas congregações, a ministração de 56 batismos naquele ano e a consagração de dois obreiros nacionais" (2008, p. 53).

Em 1884, após algum desenvolvimento dos trabalhos realizados pelos dois casais em Salvador, o 236 reverendo Willian Bagby e sua esposa Anne Bagby transferem-se para o Rio de Janeiro, onde fundam, no dia 24 de agosto, a Primeira Igreja Batista do Rio de Janeiro (ADAMOVICZ, 2008). De acordo com Elizete da Silva, "no final da década de 1880, os batistas já haviam fundado comunidades em Recife, Maceió, Rio de Janeiro. A expansão continuou pelo interior baiano, sendo que em 1915 [...] a missão baiana contava com 41 templos e dezenas de pontos de pregação, isto é, pequenos grupos em fase de organização" (2011, p. 295).

Os batistas brasileiros continuariam seu trabalho de proselitismo e sua expansão para o interior, alcançando novos estados durante as primeiras décadas do século XX. No entanto, tal expansão, efetivada pela Junta de Missões Estrangeiras de Richmond, não se configuraria em um plano institucional de evangelização, mas, permaneceriam como ações isoladas. Os missionários Erik Alfred Nelson, que fora enviado para a região amazônica em 
1891 (SANTOS, 2007), e Odilon Borges Propheta, missionário que passou pelo Vale do Rio Tocantins durante os primeiros anos do século XX (FALCÃO; NUNES, 2018) são exemplos destas ações.

Reily aponta que as ações batistas realizadas no Brasil estavam atreladas à Convenção Batista do Sul dos Estados Unidos e primavam pelo sistema de governo congregacional, ou seja, cada igreja tinha sua autonomia administrava, ainda que houvesse um forte laço entre as congregações. Para esse autor, esse congregacionalismo não impedia “(...) uma consciência da sua identidade como batistas. Esta identidade acha uma expressão estrutural ou orgânica na Convenção”. Segundo ele, a “(...) fundação da Convenção das Igrejas Batistas do Brasil, em 1907, constitui, portanto, o primeiro passo maior na nacionalização dos batistas brasileiros e na busca de uma verdadeira autonomia como denominação nacional" (2003, p. 178).

A partir de 1907, os batistas brasileiros iniciaram um processo de autonomia frente às ações desenvolvidas pelos missionários norte-americanos. No entanto, este processo de autonomização não seria realizado rapidamente ou sem causar disputas entre os líderes nacionais e os estrangeiros. Estas disputas vão resultar na chamada questão radical entre os anos de 1922 e 1925 (SILVA, 2011). Em um memorando lançado aos batistas brasileiros, pastores e líderes batistas da região nordeste manifestaram "o desejo de terem uma parte maior nas decisões quanto às prioridades e aplicação de dinheiros provindos dos Estados Unidos" (REILY, 2003, p.181).

O movimento missionário batista, de caráter institucional, isto é, vinculado a um plano institucional de evangelização e expansão para o interior do país, chegou ao Vale do Rio Tocantins em 1925. E se inicia amparado no programa intitulado A Pátria para Christo, sobre o qual tratamos a seguir. Buscamos verificar nele os elementos históricos conservadores contidos nas propostas de modernidade social e religiosa.

\section{"A PÁTRIA PARA CHRISTO": MISSIONÁRIAS E EDUCAÇÃO BATISTA NO VALE DO RIO TOCANTINS}

O programa "A Pátria para Christo" cumpriria papel fundamental no estabelecimento e manutenção dos campos missionários no centro-norte e nordeste do País. Para desenvolver o que estabeleciam as diretrizes nele contidas, a Convenção Batista Brasileira (CBB), através de sua Junta de Missões Nacionais (JMN), empreendeu um extenso plano de evangelização voltado para as populações dos vales dos rios São Francisco e Tocantins: "A Junta de Missões Nacionaes, durante o anno de 1935, continuou a desenvolver o seu plano traçado há nove anos, para tornar os rios São Francisco e Tocantins a base de suas actividades, ligando estes rios com trabalho em Barreiras, Natividade e Porto Nacional" (OJB, 23/1/1936, ed. 4, p. 3).

Nesse esforço missionário, a JMN inaugurou, a partir da chegada do casal de missionários Zacharias Campello e Noemi Campello, atividades junto às etnias indígenas que viviam especificamente no Vale do Rio Tocantins em 1926 (SILVA, 2016). Temos que ressaltar que a JMN moveu esforços visando à concretização desse programa durante vários anos. Contudo, não conseguiu, de imediato, o êxito na efetivação da conexão entre os rios através das cidades de Barreiras, Natividade e Porto Nacional. O estabelecimento da missão em Porto Nacional teria como principal empecilho a forte presença de representantes do clero católico, em especial, dos Frades Dominicanos (SANTOS, 1996).

Para vencer as resistências ao protestantismo a JMN, dez anos depois, enviaria para a região duas jovens missionárias, Beatriz Rodrigues da Silva e Lygia de Castro Martins, nascidas, respectivamente, no dia 15 de novembro de 1909 e 14 de março de 1915, 
ambas na cidade do Rio de Janeiro (SILVA, 2016). Membras da Primeira Igreja Batista, em Ricardo de Albuquerque, estudaram no Colégio Batista do Rio de Janeiro, onde se formaram professoras e missionárias. Nomeadas no final de 1935 , tornaram-se “(...) as mais novas missionárias do campo Tocantino" (OJB, 23/1/1936, ed. 4, p. 14). As duas se encaminharam para as cidades de Tocantínia e Carolina, ambas situadas às margens do Rio Tocantins, com o objetivo de auxiliar os trabalhos ali existentes na abertura de dois colégios da denominação.

Existiam, tanto em Carolina como em Tocantínia, missões batistas já estabelecidas, onde as professoras deveriam atuar em conjunto com os missionários que ali se encontravam. Carolina, em 1936, já havia se configurado como importante núcleo de povoação do Vale do Tocantins, enquanto Tocantínia se constituía em um local estratégico para o trabalho da JMN entre os indígenas, isso pela proximidade entre a localidade e aldeias indígenas (em especial as etnias Krahô e Xerente). É importante ressaltar que os povos indígenas situados ás margens do Rio Tocantins já mantinham contato com missionários batistas no norte de Goiás há pelo menos 10 anos, desde a chegada dos casais Campello e Colares na região.

A partir de abril de 1936 já se tem notícias das missionárias e dos Colégios organizados por elas na região. Logo que chegaram, as duas fizeram questão de ligar suas ações aos poderes locais, dando destaque às autoridades que as receberam, o que aponta para as ações de formação do campo religioso, pois, segundo Pierre Bourdieu (2007), esse se faz com ações religiosas, mas também com aproximações políticas. Pudemos acompanhar essa tentativa de aproximação em outras narrativas das próprias missionárias, publicadas por meio de cartas e relatórios oficiais no OJB, sobretudo nas seções da JMN e da União Geral de Senhoras do Brasil (UGSB).
O foco principal dos trabalhos de Beatriz Silva e Lygia de Castro se constituía na organização de colégios, uma vez que nas duas localidades já se encontravam organizados trabalhos missionários de cunho estritamente religioso. Beatriz Silva, chegando a Piabanha no dia 28 de fevereiro, inauguraria um colégio no mesmo dia, com o auxílio do casal Campello. De Carolina, a primeira notícia vem de uma carta de Normando Lang, pastor batista da cidade, publicada em 9 de abril, na qual informa sobre a receptividade encontrada:

\begin{abstract}
Antes de partir de Carolina fiz grande propaganda para a Escola, que esperamos será aberta em princípios de Março. O povo em geral está ansioso de ver aberta esta escola, e esperamos que muitos paes nos entregarão seus filhos, afim de que recebam uma educação evangélica. Falando um dia ao Prefeito de Carolina, elle ofereceu-nos o empréstimo de vinte carteiras duplas para a escola e com certas modificações no mesmo edifício da Igreja, fizemos um bom salão para a Escola. Alguns paes estão pedindo logar para os filhos (OJB, 9/4/1936 ed. 15 , p. $11-12$ ).
\end{abstract}

Publicar a contribuição de políticos e autoridades locais fazia parte da estratégia de colocar suas ações como necessárias à região. As atividades educacionais e religiosas não se davam, todavia, de forma tranquila, dadas as animosidades entre católicos e protestantes. São recorrentes os relatos de conflitos entre católicos e batistas na região (SILVA, 2016). Esses conflitos ocorriam em razão da disputa dos dois grupos pela hegemonia da gestão dos bens de salvação (BOURDIEU, 2007). No entanto, podemos perceber certa adesão aos colégios batistas por parte da população da região. Em Carolina, o Colégio Rosalee Appleby registrou, no início de 1937, a quantidade de 85 matrículas (OJB, 20/5/1937, p. 6 -7), enquanto no Colégio Batista de Tocantínia o número de matrículas chegou a 65. Em ambos os casos, o dobro registrado para o ano anterior.

A partir de anúncios veiculados no periódico A Tarde (editado e publicado em Carolina durante o 
período em que compreende este estudo) e do livro de biografias de Beatriz Rodrigues da Silva (escrito por Margarida Lemos Gonçalves), podemos percorrer, ainda que brevemente, as orientações pedagógicas seguidas pelas duas professoras nos colégios. Segundo um anúncio publicado no jornal em 1936: "a Escola Baptista de Carolina conta com a vossa leal cooperação para que possa de uma maneira real e proveitosa ministrar as creanças o conhecimento que as fará melhores em sua relação para com o Lar, a Sociedade e a Pátria" (A TARDE, 15/03/1936, N. 327, p. 4).

Neste anúncio encontram-se ainda outras informações importantes para a compreensão da proposta escolar batista, como a ideia de que as mestras atuavam a partir de um "programma" educacional, que seria ministrado no Colégio de Carolina pela professora Lygia de Castro Martins. Em um período em que as escolas primárias da região ainda buscavam uma proposta pedagógica clara, as missionárias eram tidas como detentoras de uma proposta eficiente, como demonstrado no relatório do inspetor Gustavo Serrão Porto Gonçalves. Para atender as crianças com o ensino primário, as disciplinas ministradas seriam "Portuguez, Arithmetica, Geometria e Desenho, H. do Brazil, Sciencias, Geographia, Trabalhos Manuais e Hygiene" (A Tarde, 15/03/1936, N. 327, p. 4). Segundo o artigo, este currículo era o mesmo para todos os anos, com a inclusão da disciplina de Música a partir do $3^{\circ}$ ano, o que demonstra a proposta de uma educação que colabora para melhores relações "com o Lar, a Sociedade e a Pátria", além de materializar, conforme buscamos salientar no artigo, como a educação escolarizada poderia contribuir para espraiar, através da religiosidade batista, uma prática cultural própria da visão de mundo dos protestantes.

Apesar de não dispormos de documentação impressa que aborde diretamente as orientações seguidas por Beatriz Rodrigues da Silva no Colégio Batista de Tocantínia (uma vez que no local não havia tipografias à época e as mais próximas encontravamse na cidade de Porto Nacional, até então uma grande dificuldade para os religiosos batistas), podemos estender este programa educacional para todos os colégios mantidos pela JMN na região. Não se trata de afirmar que as diferentes professoras detivessem uma prática pedagógica única, mas, que a partir de sua vinculação para com a JMN, estas receberiam as mesmas orientações e os mesmos materiais, no objetivo de padronizar a atuação batista por toda a região do Vale do Rio Tocantins.

Podemos confirmar este alinhamento das orientações de ensino entre os colégios de Carolina e Tocantínia por meio do livro de biografias de Beatriz Rodrigues da Silva, A missionária que veio para ficar, escrito pela missionária Margarida Lemos Gonçalves (2011). Neste trabalho, a autora descreve algumas das facetas da atuação da professora. Ela afirma que eram mantidas no colégio algumas associações que atuariam segundo as orientações religiosas contidas no anúncio do colégio de Carolina, o que configura uma educação escolarizada que objetivava a conversão social e religiosa - a generalização de religião e civilização voltada para "o Lar, a Sociedade, e a Pátria":

1. O Pelotão de Saúde, responsável pela higiene do aluno (do corpo e dos utensílios escolares), bem como da sala de aula e até do ambiente em que o aluno se envolvia no lar. (...) 2. O Grêmio Lítero-Esportivo Rui Barbosa, que cuidava da vida intelectual dos alunos, incentivando a leitura, organizando festas, criando músicas, promovendo competições literárias, tudo com o objetivo de trabalhar a vida dos cidadãos de amanhã. (...) 4. A "Associação de Alunos Evangélicos", que surgiu após a implantação do Curso Fundamental e do Médio, cuja função era não apenas aperfeiçoar a vida cristã dos alunos crentes, mas também evangelizar os que não conheciam Jesus (GONÇALVES, 2011, p. 2224).

Devemos lembrar ainda que as sentenças sobre higiene e saúde estavam afinadas aos dizeres 
médicos e sanitaristas da primeira metade do século XX. Como demonstrado anteriormente, e muito divulgadas nas regiões do interior e nos grandes centros urbanos, esses debates contribuíam para a representação destas regiões como doentes e insalubres, e que os protestantes, ao empreenderem uma educação escolar neste sentido, inseriam-se nestes debates representativos da solução para os problemas espirituais, físicos e morais das populações da região do Vale do Rio Tocantins, numa perspectiva de moldar culturas tidas como avessas ao processo civilizador nos sertões.

Em 1939, os trabalhos nos colégios de Carolina e Tocantínia seguiram em ritmo mais acelerado do que nos anos anteriores, atendendo quantos alunos fosse possível. O número de matrículas no Colégio Batista de Tocantínia, segundo relato de Beatriz Silva, efetivou-se em 100, não sendo maior "por falta de energia pessoal e incapacidade do salão de aulas", além de contar com "mais de dez adultos que estudam no colégio, sendo que algumas senhoras da Igreja também se preparam para melhor servirem". Em Carolina, no mesmo ano, o número de matrículas efetivadas no Colégio Rosalee Appleby encerrou-se em 85 (OJB, 6/7/1939, ed. 27, p. 8).

No início de 1940, o OJB publicou o Relatório Anual da Junta de Missões, no qual foi informada a quantidade de alunos matriculados nas escolas batistas no ano anterior “(...) escolas diárias, 6; alunos matriculados nas mesmas, 327" (OJB, 18/1/1940, ed. 3 , p. 7), demonstrando que os resultados das ações educacionais e evangelísticas de Beatriz Silva e Lygia de Castro foram positivos.

As missionárias foram fundamentais para a consolidação da denominação batista no Vale do Rio Tocantins. E atuavam não apenas nos locais dos colégios, mas em toda a extensão do trabalho batista, sendo, em alguns casos, as primeiras a transpor os limites de algumas localidades ocupadas pelo clero católico. Durante o ano de 1940, as matrículas nos colégios de Carolina e Tocantínia se mantiveram em alta, registrando, respectivamente, 85 e 100 alunos cada um (OJB, 4/7/1940, ed. 27, p. 7 - 10).

\section{PALAVRAS FINAIS}

As narrativas de levar o evangelho e a educação escolar aos sertões demarcariam o espaço dos batistas na região, e essas seriam desenvolvidas com base em concepções etnocêntricas dos conceitos de religião e civilização (MASSENZIO, 2005). Como vimos, não só os protestantes, mas, vários segmentos da sociedade republicana nas primeiras décadas do século $\mathrm{XX}$, mantinham em seus discursos um caráter etnocêntrico e conservador em relação ao interior do país e as populações tradicionais daquelas regiões. A relação progresso/atraso presente nos discursos dos sanitaristas (CAIXETA, 2014), nos textos de literatos e intelectuais (SEVCENKO, 1999) e mesmo nos discursos dos missionários, demonstrava a defesa de uma sociedade que se julgava civilizada e saneada, sobrepondo-se à outra, definida por eles como atrasada, doente e em trevas. O modo com que os evangélicos protestantes enxergam os que não coadunam com seu modelo de cristianismo não é algo recente.

As práticas religiosas e educacionais de missionários e missionárias estavam inseridas, dessa forma, no contexto da modernidade republicana, o que não quer dizer que os projetos desenvolvidos pelos protestantes durante as primeiras décadas do século XX estivessem a serviço única e exclusivamente das forças políticas que dominavam o debate intelectual do país. O que queremos dizer é que, a partir desse contexto histórico, esses religiosos se movimentaram em sintonia com outras forças que procuravam ditar o modelo de civilização pretendido para as regiões do interior. E realizaram isso muito em decorrência dos 
valores civilizatórios e religiosos que marcavam um protestantismo gestado em outros lugares.

O que as publicações no "O Jornal Batista" e as práticas educacionais das missionárias que implantaram escolas no Vale do Rio Tocantins revelam? Que o evangelismo protestante, que não concebe as culturas indígenas, quilombolas, ribeirinhas e outras de natureza popular, portanto um evangelismo conservador, não emergiu somente na década de 1970. Ele foi praticado já nas primeiras décadas do século XX, no bojo da implantação da República. Podemos afirmar que ele está no âmago das religiões proselitistas, ou seja, das conversões religiosas.

Todos os autores declararam não haver qualquer potencial conflito de interesses referente a este artigo.

\section{REFERÊNCIAS}

ADAMOVICZ, Anna Lúcia Collyer. Imprensa Protestante na Primeira República: Evangelismo, informação e produção cultural. O Jornal Batista (1901-1922). 2008. 400 f. Tese (Doutorado) Faculdade de Filosofia, Letras, História e Ciências, Universidade de São Paulo, São Paulo, 2008.

ALMEIDA, Luciane Silva de. Da Defesa do Estado Laico à "Revolução Enviada por Deus": protestantes históricos e política no Brasil, um breve histórico (1900 - 1970). In: Os 500 Anos da Reforma Protestante no Brasil: um debate histórico e historiográfico / Lyndon de Araújo Santos, Elizete da Silva, Vasni de Almeida (Organizadores). - Curitiba: CRV, 2017.

ALMEIDA, Vasni de. Protestantismo e República no Brasil. In: SILVA, Elizete da, SANTOS, Lyndon de Araújo; ALMEIDA, Vasni de. Os 500 anos da Reforma Protestante no Brasil: um debate histórico e historiográfico. Curitiba, PR: Editora CRV, 2017.

BOURDIEU, Pierre. Gênese e estrutura do Campo Religioso. In: A economia das trocas simbólicas. São Paulo: Perspectiva, 2007, p. $27-78$.

CAIXETA, Vera Lúcia. Médicos, frades e intelectuais: leituras sobre os sertões do Brasil Central (1882 - 1935). / Vera Lúcia Caixeta. - 1. a ed. Curitiba, PR: CRV, 2014.
CAMPOS, Leonildo Silveira. O protestantismo de missão no Brasil, cidadania e liberdade religiosa. São Paulo: Revista Educação e Linguagens, vol. 17, n. ${ }^{\circ}$ 1, jan./jun. 2014, p. 76-116. Disponível em: https://www.metodista.br/revistas/revistasmetodista/i ndex.php/EL/article/view/5493. Acesso em 11 jan. 2017.

DREHER, Martin. Apresentação. In: "Fiél é a Palavra": Leituras Históricas dos Evangélicos Protestantes no Brasil / Elizete da Silva, Lyndon Araújo dos Santos, Vasni de Almeida (Organizadores). - Feira de Santana: UEFS Editora, 2011 .

ELEUTÉRIO, Maria de Lourdes. Imprensa a Serviço Do Progresso. In: História da Imprensa no Brasil/ Ana Luiza Martins e Tania Regina de Luca, (organizadoras). - 2. ${ }^{\text {a }}$ ed. - São Paulo: Contexto, 2011.

FALCÃO, Matheus Silva; NUNES, Radamés Vieira. Cosmovisão Protestante: modernização e religião no Norte de Goyaz (1905 - 1925). Mediação, Pires do Rio-GO, v. 13, n. ${ }^{\circ}$ 2, p. 46 - 61, jul./dez. 2018. ISSN 1980-556X (versão impressa) / e-ISSN 2447-6978 (versão on-line).

GONÇALVES, Margarida Lemos. A missionária que veio para ficar / Margarida Lemos Gonçalves. -

HOORNAERT, Eduardo. A Igreja Católica no Brasil Colonial. In: História da América Latina: América Latina Colonial, volume I/ organização Leslie Bethell; tradução Maria Clara Cescato. - 2. ${ }^{\mathrm{a}}$ ed. 2. Reimpr. - São Paulo: Editora da Universidade de São Paulo, 2008.

JORNAL A TARDE. SOLICITADAS: ESCOLA BAPTISTA DE CAROLINA. Carolina: Maranhão, Ano X, N. 327, 15 de Março de 1936.

LEONARD, Émile-Guillaume. O protestantismo brasileiro: estudo de eclesiologia e história social. Trad. Linneu Camargo Schützer. São Paulo: ASTE, 1963.

MASSENZIO, Marcelo. A História das Religiões na Cultura Moderna. São Paulo: HEDRA, 2005.

O JORNAL BATISTA. Convenção Batista Brasileira. Rio de Janeiro, 1925 a 1942. Disponível em: http://www.convencaobatista.com.br/siteNovo/buscas /jornalBatista.php

REILY, Ducan Alexander. História documental do protestantismo no Brasil. $-3^{a}$ ed. São Paulo: ASTE, 2003. 
SANTOS, João Marcos Leitão. A concepção da ordem social segundo o protestantismo brasileiro: 1891-1930. Juiz de Fora, MG. PLURA, Revista de Estudos de Religião, ISSN 2179-0019, vol. 3, n. ${ }^{\circ} 2$, 2012, p. 131-158.

SANTOS, Catarina Maria Costa dos. A Terra prometida: discursos, práticas e imagens da presença dos batistas brasileiros na Amazônia (1970-1980) / Catarina Maria Costa dos Santos; orientadora, Magda Ricci. - 2007.

SANTOS, Edivaldo Antonio dos. Os dominicanos em Goiás e Tocantins $(1881$ - 1930): fundação e consolidação da missão dominicana no Brasil. Dissertação de Mestrado. Mestrado em História das Sociedades Agrárias da Universidade Federal de Goiás. Goiás - GO, 1996.

SANTOS, Lyndon de Araújo. O protestantismo no Advento da República no Brasil: discursos, estratégias e conflitos. Maringá, PR: Revista Brasileira de História das Religiões, ANPUH. Ano III, n. ${ }^{\circ}$ 8, set. $2010 . \quad$ Disponível em: http://www.dhi.uem.br/gtreligiao. Acesso em 18 jan. 2017.
SEVCENKO, Nicolau. Literatura como Missão: tensões sociais e criação cultural na Primeira República. 1. ${ }^{a}$ ed. São Paulo: Companhia das Letras, 1999.

SILVA, Elizete da. Os Batistas no Brasil. In: "Fiél é a Palavra": Leituras Históricas dos Evangélicos Protestantes no Brasil / Elizete da Silva, Lyndon Araújo dos Santos, Vasni de Almeida (Organizadores). - Feira de Santana: UEFS Editora, 2011.

SILVA, Elizete da. A Reforma Protestante e o Mundo Moderno. In: Os 500 Anos da Reforma Protestante no Brasil: um debate histórico e historiográfico/ Lyndon de Araújo Santos, Elizete da Silva, Vasni de Almeida (Organizadores). Curitiba: CRV, 2017.

SILVA, Paulo Julião da. Entre a Evangelização e a Política: A Expansão Missionária Batista para o Brasil Central (1925 - 1939). Tese (Doutorado) Universidade Estadual de Campinas, Instituto de Filosofia e Ciências Humanas, SP: [s.n.], 2016.

SILVA, Elizete da. O protestantismo e as questões sociais. Feira de Santana, BA: Revista Sitientibus, n. ${ }^{\circ}$ 14, p. 129-142, 1996. Disponível em: www2.uefs.br/sitientibus/pdf/14/protestantismo_e_qu estoes_sociais.pdf. Acesso em 9 jan. 2017. 